\title{
О ФОРМИРОВАНИИ ЭКОНОМИКИ ЗНАНИЙ
}

\author{
Фаркова Н.А.
}

На современном этапе экономику называют «экономикой знаний». Новая роль знания (или также доступа к знанию, владения знанием) проявляется в признании знания важнейшим источником успеха в конкурентной борьбе экономических субъектов на глобальном рынке. Однако само понятие «знания» неоднородно.

DOI: $10.20537 /$ mce2020econ 18

У каждой цивилизации есть своя модель функционирования общества и экономики. Изменение цивилизационной парадигмы вытесняет прошлые модели не только экономики в целом, а также управления, инвестирования, торговли, образования, работы, занятости, потребления и даже порядка в семье, которые быстро теряют актуальность. Меняется большинство методов общения, производства и торгового обмена.

В 1962 г. Ф. Махлуп, анализируя изменения в структуре экономики, выявил решающую роль знаний для инновационного развития. Ему принадлежит и авторство термина «экономика знаний». Исследования, проведенные в 80-90-ых гг. в странах с различным уровнем развития, показали существенное влияние на экономическое развитие как отечественных, так и зарубежных научно-исследовательских и опытноконструкторских разработок (НИОКР). Отметим, что около 40\% общемировых затрат на НИОКР принадлежат США. Еще в конце XX века по оценкам известного американского ученого Питера Друкера работники знаний составляли около $40 \%$ всей рабочей силы в США. В других развитых странах доля этой группы меньше, но она неуклонно возрастает [1]. «Общество будущего будет интеллектуальным. Знания станут его основным ресурсом, а интеллектуальные работники станут основной группой в армии рабочей силы», — делает вывод П. Друкер.

Анализируя процессы в истории общественно-экономического развития мира, А. Тоффлер выделил три волны: аграрное общество первая волна, индустриальное общество - вторая волна, постиндустриальное (информационное) общество — третья волна (рис. 1). 


\section{Постиндустриатьное oбuecmeo}

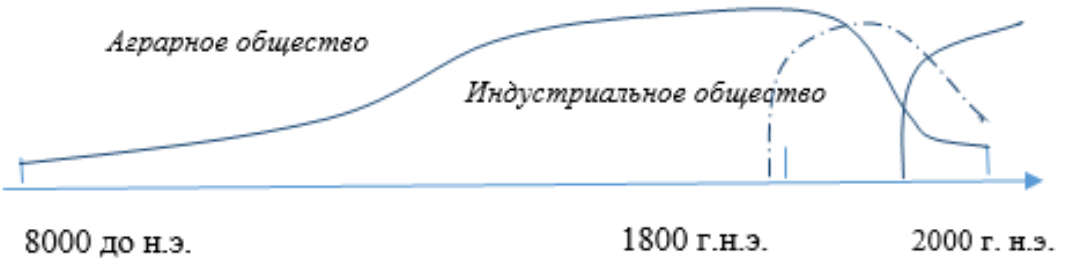

Рис. 1. Три волны Тоффлера.

Социально-экономическое развитие на его отдельных этапах с учетом связанных с ним ресурсов представлен на рис. 2.

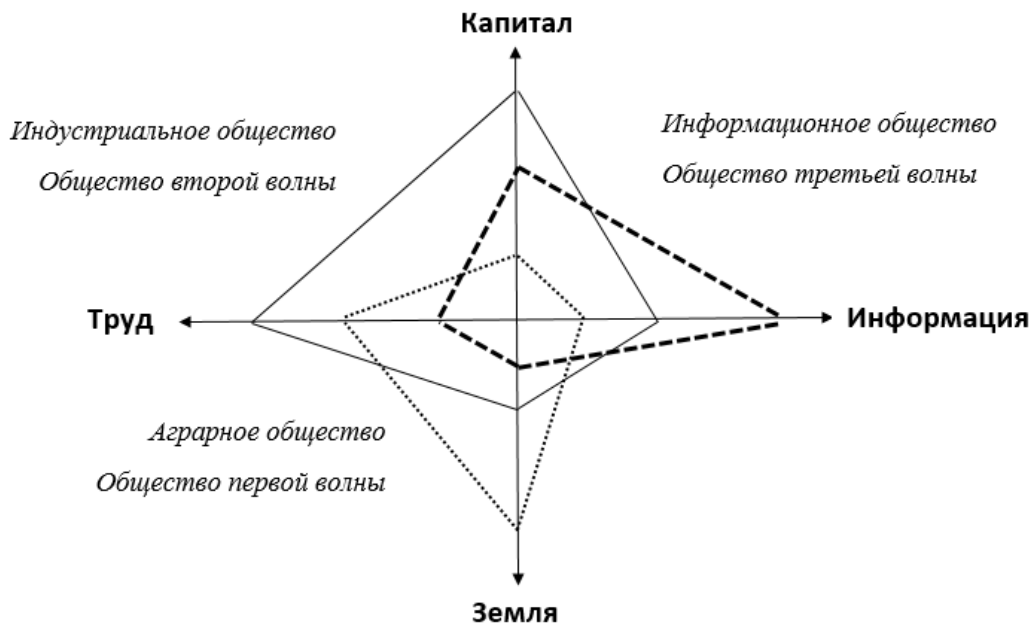

Рис. 2. Участие ресурсов в экономическом развитии. 
В постиндустриальном обществе доставка и переработка информации стали основой создания национального дохода и источником существования для значительной части граждан. В последнее десятилетие все чаще говорят не об информационном обществе, а об обществе знания, подчеркивая, что именно теоретическое знание, его креативное использование и доступ к современным технологиям стали источником богатства и экономического развития. Чтобы объяснить разницу в аспектах использования упомянутых понятий, следует различать знание и информацию.

Не существует единого определения понятия «экономики знаний». Некоторые за основу принимают уровень развития информационных технологии и высокотехнологичных отраслей, другие акцентируются на масштабах накопленного и обращающегося в обществе знания. Согласно Всемирному Банку экономика становится «экономикой знаний», когда главным фактором в процессе экономического развития является непрекращающееся использование и создание знания. Экономика знаний - та, которая использует знание как главную движущую силу экономического роста. В такой экономике знание усваивается, создается, передается и используется для ускорения экономического развития.

С другой стороны, экономика знаний - это такая экономика, в которой действуют многие предприятия, основывающие свое конкурентное преимущество на знании.

В связи с функционированием понятий «информационная экономика» и «экономика знания» стоит разделять эти понятия. Это представляет рис. 3. Правая сторона треугольника включает объяснения данных, информации и знания, а левая - их примерное использование. Пусть дана цена 70 рублей. Если эта цена будет размещена в контексте курса валют, например, в отношении к 1 евро, то она станет информацией. Если эта информация, в свою очередь, будет интерпретирована лицом, работающим на валютном рынке, то мы уже имеем дело со знанием.

Однако, и само понятие «знание» не однородно, что нельзя не учитывать в контексте строительства экономики знания.

Если за критерий принять место возникновения знания и его доступность, то выделяют: 
- явное знание (формальное), (explicit knowledge) - это организованное, систематизированное, записанное знание, которое может храниться и передаваться различными способами, например, в книгах, докладах, патентах, базах данных, в Интернете и т.д. Это знание характеризуется легкой доступностью и возможностью использования.

- неотделимое ${ }^{*}$ знание (молчаливое, скрытое), (tacit knowledge), которое мы используем в повседневной жизни, но не можем до конца определить, а из-за этого его формализация и передача другим людям очень затруднена. Неотделимое знание накапливается вместе с опытом у каждого человека, но, несмотря на это, мы не можем его ясно определить и уточнить.

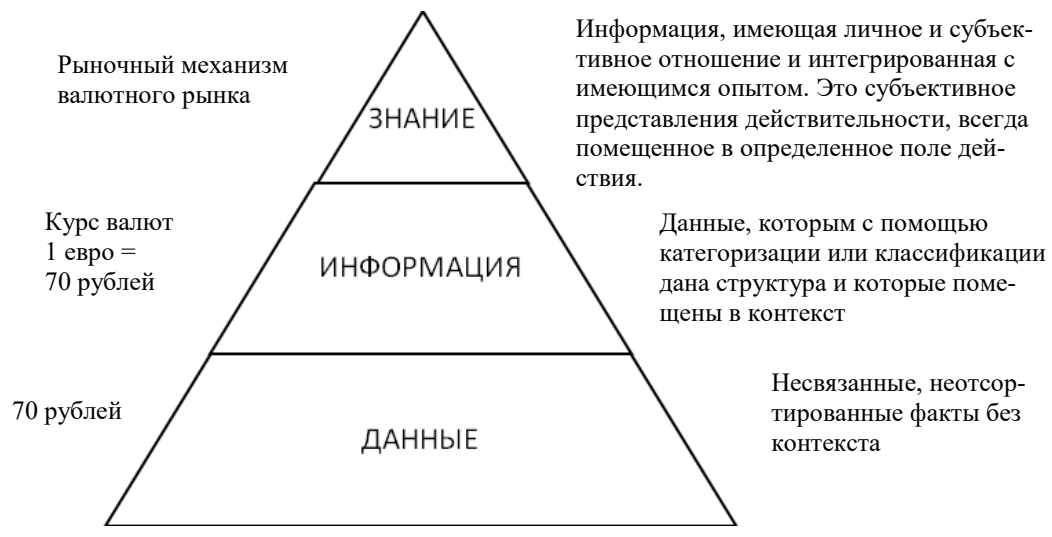

Рис. 3. Иерархия знания.

\footnotetext{
* Общепринятый перевод, см. Макаров В.Л., Варшавский А.Е., Козырев А.Н. Основные показатели и проблемы перехода России к экономике, базирующейся на знаниях / Глава 6 в кн. Инновационный менеджмент в России: вопросы стратегического управления и научно-технологической безопасности / Руководители авт. колл. В.Л.Макаров, А.Е.Варшавский. - М.: Наука 2004. (прим. ред.)
} 
Б. Лундвалль и Б. Джонсон [3] предложили другую классификацию знания:

- know-what (знать что) - относится к знанию фактов. Сколько человек живет в Нью-Йорке, из чего делают блины, когда состоялась Грюнвальдская битва — это примеры такого знания. Здесь знание ограничено информацией - оно может быть разделено на фрагменты и легко передано как данные.

- know-why (знать почему) - это знание о причинноследственных отношениях, касающихся прав природы, человека и общество. Этот вид знания неизменно важен для технологического развития в определенных областях, основанных на науке, таких, например, как химическая или электрическая промышленность. Доступ к такому роду знания будет влиять на более быстрый технический прогресс.

- know-how (знать как) - это знание, относящееся к умению, то есть, способности делать что-то; это знание, которым обладают эксперты и которое накапливается посредством опыта, которым они овладели, а также опыта, накопленного фирмой; публичный доступ к такому виду знания очень ограничен, а его передача трудна.

- know-who (знать кто) - охватывает информацию о том, кто что знает и кто знает, что делать. Задача - выявление обладателей знания, доступ к ним и использование их знаний. Оно также охватывает социальную способность к кооперации и коммуникации с разными людьми и экспертами.

Относя эту типологию к процессам развития, можно сказать, что в успешных попытках создания инновационных решений решающую роль играет неотделимое знание (tacit knowledge), охватывающее практические способности достижения желаемых результатов (know-how) и способность разобраться в человеческих ресурсах, что облегчает совместную деятельность (know-who). Это знание нельзя сегодня сократить до однозначно явного знания, касающегося фактов (know-what), как и до научно признанных закономерностей (know-why).

Согласно исследованиям, проведенным Институтом Всемирного Банка, условием развития экономики знаний является существование:

- институциональной и экономической среды, облегчающей свободную передачу знания, инвестиций в информационные и коммуникационные технологии и поощряющей развитие предпринимательства; 
- образованного общества, обладающего навыками создания, использования (в том числе совместного использования) знания;

- динамичной информационной инфраструктуры, облегчающей эффективное создание, распространение и обработку информации;

- сети исследовательских центров, университетов, групп консультантов, частных предприятий и гражданских групп на местном уровне, которые позволили бы использовать растущие ресурсы глобального знания, поглощать и адаптировать их к местным потребностям и создавать новое знание.

Поскольку экономика знаний вырастает из индустриальной экономики, в которой главным ресурсом является товар (рабочая сила, земля или капитал), то движущая сила дальнейшего развития экономики знаний формируется во взаимодействии отношений, завязанных на категориях «информация и знания», «товар».

Знание имеет ряд особенностей, которые определяют необходимость его обращения на рынке и в то же время приводят к ограниченности возможных рыночных взаимодействий в областях, связанных с ним. Такие свойства знания как неполнота, ограниченность информации, «рассеянность» среди людей и, то, что знание находится в голове человека и не всегда может быть формализовано, приводит к необходимости создания специальных институтов, позволяющих использовать знание как производственный ресурс наравне с другими ресурсами.

Рыночным товарам присущи следующие три свойства:

- полезность - способность удовлетворять некоторую потребность;

- $\quad$ редкость - отсутствие избытка, не востребованного ни по какой положительной цене;

- универсальность - способность к обмену на другие рыночные товары.

Сравнивая свойства знания или информации и товара, прежде всего отметим, что знание и информация в отличие от товара после потребления не исчезает, а наоборот, нарастает. И если товар после продажи переходит от владельца к потребителю, то информация и знание остается у владельца и появляется у потребителя.

Итак, к знанию не применимы ни теорема редкости (чем более редок товар, тем выше его цена, поскольку спрос на товар во многом может превышать возможности его удовлетворения), ни теорема стоимо- 
сти (стоимость есть овеществленный в товаре общественно необходимый труд), которые справедливы для товара.

К причинам неприменимости указанных теорем можно отнести невозможность установления общественного стандарта издержек на «производство» определенного знания, поскольку это во многом зависит от способностей человека. Ценность знания или информации зависит не от издержек на ее получение, а от важности решений или новой информации, вызываемых ее использованием. Кроме того, чем больше людей обладают информацией, тем выше ее потенциальная ценность [4].

Отметим, что в целом же применение товарной концепции полезности к информации не вполне корректно. По своей природе знание и информация не может иметь цены ни с точки зрения теории стоимости, ни с позиций теории полезности. При этом мы повсеместно наблюдаем, что информация и знания продаются и покупаются по конкретным ценам. В реальной жизни для данного противоречия находятся способы разрешения. Знание или информация, не являясь по своей природе товаром и будучи в чем-то противоположным товару, вынуждены в среде товарно-денежных отношений приобретать товарную форму.

В заключении приведем оценки рейтинга стран Всемирного Банка по различным индексам (табл. 1). В Индексе экономики знаний (ИЭЗ) берется во внимание, способствует ли обстановка в данной стране эффективному использованию знания для экономического развития, в то время как Индекс знаний отражает способность страны генерировать и адаптировать знания.

Оценка рейтинга для России показывает, что на современном этапе развития российская институциональная среда не в состоянии разрешить проблемы, связанные с созданием условий для роста технологий и экономики основанной на знании. 
Анализ и моделирование экономических и сочиальных прочессов - МКО - 2020

Analysis and modeling of economic and social processes - MCE - 2020

Таблица 1. Индексы экономики знаний и индекс знаний. Источник: [5]

\begin{tabular}{|c|c|c|c|c|c|c|c|c|}
\hline 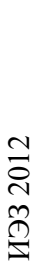 & 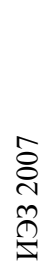 & $\begin{array}{l}\text { 芯 } \\
\text { 芯 } \\
\mathcal{E}\end{array}$ & 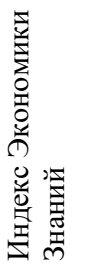 & 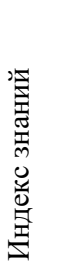 & 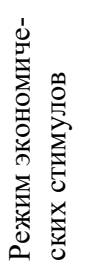 & 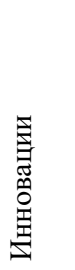 & 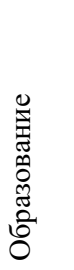 & 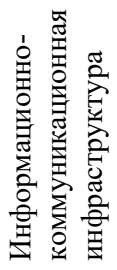 \\
\hline 1 & 1 & Швеция & 9.43 & 9.49 & 8.59 & 9.72 & 8.98 & 9.76 \\
\hline 3 & 2 & Дания & 9.16 & 9.30 & 8.97 & 9.43 & 9.22 & 9.25 \\
\hline 5 & 3 & Норвегия & 9.11 & 9.08 & 9.45 & 8.86 & 9.20 & 9.17 \\
\hline 2 & 4 & Финляндия & 9.33 & 9.10 & 8.95 & 9.60 & 9.20 & 8.52 \\
\hline 14 & 9 & $\begin{array}{l}\text { Великобри- } \\
\text { тания }\end{array}$ & 8.76 & 8.88 & 8.54 & 9.21 & 8.50 & 8.93 \\
\hline 12 & 10 & США & 8.77 & 8.91 & 8.45 & 9.44 & 8.35 & 8.95 \\
\hline 17 & 13 & Австрия & 8.58 & 8.55 & 8.69 & 8.82 & 8.08 & 8.75 \\
\hline 11 & 14 & Ирландия & 8.86 & 8.57 & 8.54 & 8.92 & 8.62 & 8.16 \\
\hline 8 & 15 & Германия & 8.09 & 8.60 & 8.38 & 8.93 & 8.08 & 8.75 \\
\hline 15 & 16 & Бельгия & 8.71 & 8.55 & 8.19 & 8.93 & 8.72 & 8.01 \\
\hline 22 & 17 & Япония & 8.28 & 8.62 & 7.99 & 9.17 & 8.20 & 8.47 \\
\hline 24 & 20 & Франция & 8.21 & 8.48 & 8.02 & 8.59 & 8.52 & 8.31 \\
\hline 28 & 23 & Словения & 8.01 & 8.36 & 7.57 & 8.18 & 8.54 & 8.34 \\
\hline 21 & 24 & Испания & 8.35 & 8.08 & 8.09 & 8.09 & 8.42 & 7.74 \\
\hline 19 & 25 & Эстония & 8.40 & 8.07 & 8.07 & 7.42 & 8.29 & 8.49 \\
\hline 30 & 26 & Италия & 7.89 & 8.21 & 7.30 & 8.05 & 7.86 & 8.72 \\
\hline 27 & 28 & Венгрия & 8.02 & 7.64 & 7.64 & 8.18 & 7.68 & 7.08 \\
\hline 26 & 29 & Чехия & 8.14 & 7.65 & 7.59 & 7.67 & 7.59 & 7.69 \\
\hline 35 & 30 & Кипр & 7.56 & 7.49 & 8.04 & 7.64 & 6.61 & 8.22 \\
\hline 37 & 31 & Литва & 7.41 & 7.51 & 7.45 & 6.43 & 8.30 & 7.79 \\
\hline 34 & 32 & Португалия & 7.61 & 7.25 & 8.02 & 7.40 & 6.93 & 7.43 \\
\hline 32 & 33 & Латвия & 7.80 & 7.41 & 7.26 & 6.44 & 8.35 & 7.45 \\
\hline 36 & 34 & Греция & 7.51 & 7.26 & 7.38 & 7.62 & 7.56 & 6.60 \\
\hline 38 & 35 & Польша & 7.41 & 7.29 & 7.07 & 6.89 & 8.11 & 6.87 \\
\hline 33 & 36 & Словакия & 7.64 & 7.17 & 7.38 & 6.95 & 6.92 & 7.63 \\
\hline 39 & 38 & Хорватия & 7.29 & 7.05 & 7.23 & 7.58 & 6.47 & 7.09 \\
\hline 45 & 41 & Болгария & 6.80 & 6.63 & 4.84 & 6.56 & 7.34 & 5.99 \\
\hline 55 & 47 & Россия & 5.78 & 6.92 & 2.99 & 6.92 & 7.66 & 6.19 \\
\hline 44 & 48 & Румыния & 6.82 & 5.89 & 5.77 & 5.69 & 5.91 & 6.09 \\
\hline 56 & 51 & Украина & 5.73 & 5.88 & 4.67 & 5.78 & 7.54 & 4.32 \\
\hline
\end{tabular}




\section{СПИСОК ЛИТЕРАТУРЫ}

1. Drucker P.F. Management Challenges for the 21 st Century / P.F. Drucker. Oxford: Elsevier, 1999.

2. Тоффлер Э. Третья волна. М.: Издательство АСТ, 2004.

3. Lundvall B.-A. The economics of knowledge and learning / J.L. Christensen, B.A. Lundvall (eds.), Product Innovation, Interactive Learning and Economic Performance, Research on Technological Innovation, Management and Policy. Elsevier, Amsterdam, 2004.

4. Крыштафович А.Н. Повышение результативности деятельности работника знаний // Банкаўскі веснік. 2016. № 12. С. 62-67; 2017. № 1. С. 67-71.

5. Индекс экономики знаний // Министерство цифрового развития, связи и массовых коммуникаций Российской Федерации. URL:

https://digital.gov.ru/ru/activity/statistic/rating/indeks-ekonomikiznanij/\#tabs\%7CCompare:Place

\section{THE FORMATION OF THE KNOWLEDGE-BASED ECONOMIC}

\section{Farkova N.A.}

It is conventional to represent the current stage of economic development as the «knowledge-based» economy. The new role of knowledge (or also access to knowledge, possession of knowledge) is manifested in the recognition of knowledge as the most important source of competitiveness of economic agents in the global market. However, the very concept of "knowledge" is heterogeneous. 